\title{
The Neolithic Revolution: agriculture, sedentary lifestyle and its consequences
}

\section{INTRODUCTION}

The adoption of agriculture in the Neolithic was one of the most important events in human history. The appearance and subsequent expansion of agriculture in different areas of the planet took place approximately 10,000 to 5,000 years ago. Before that, humans used hunter-gatherer techniques to procure their livelihood. The transition to agriculture, which later led to the emergence and development of the first urban civilizations, allowed to obtain an unimaginable wealth and material prosperity for the Neolithic hunter-gatherer populations, which has caused this process to have been called the "Neolithic Revolution"". However, not all were advantages. In some cases, the adoption of agriculture and a sedentary way of life had consequences whose effects are being felt today.

Establishing where and when humans decided to domesticate certain animals and plants is relatively well known, as well as their theories. Establishing where and when humans decided to domesticate certain animals and plants is relatively well known, as well as their theories. What remains a topic of discussion is the reason that prompted our ancestors to adopt a way of life so radically different from the one they had led for generations.

Traditionally, the adoption of agriculture has been perceived as positive, and that human beings assumed this new way of life after realizing the advantages of domestication of certain species to obtain a constant flow of food resources. Recently, various studies have cast doubt on this fact by stating that agricultural work requires greater physical effort and dedication than hunting and gathering. Finding a convincing answer to explain the reasons for this decision is a question that has been the subject of various speculations for decades. Most researchers agree that there is no single explanation for this transition (Harlan 1995; Smith 1995; Fernández-Armesto, 2001), which arose independently in various areas of the planet and later spread to others. In the

\footnotetext{
${ }^{1}$ This term was coined in 1936 by Gordon Childe, although some researchers prefer to use the term "Agricultural Revolution".
} 
Mediterranean basin, it spread from the Fertile Crescent ${ }^{2}$ thanks to the prosperity achieved in that area after the adoption and development of agriculture.

\section{ON THE ORIGIN AND ADOPTION OF AGRICULTURE}

It is undeniable that the appearance and expansion of agriculture during the Neolithic has had consequences of great relevance in the subsequent development of Humanity. That is why it is still necessary to inquire about its origin and the reasons that led to its adoption, issues that have given rise to numerous hypotheses.

For Winterhalder and Kennett (2006: 4-5). there are three variables that would explain the origin of agriculture, which are:

- increasing demographic pressure.

- a change in environmental conditions.

- the emergence of socioeconomic competition.

Regarding the first of them, Mark Cohen (1977) proposed as a reason for the adoption of agriculture the presence of an imbalance of available resources due to the growth of human demographic pressure in certain areas of the planet. This prompted groups of hunter-gatherers to consider adopting a completely different way of life in the late Pleistocene ${ }^{3}$. A possible criticism of Cohen's proposal is that it does not explain why the human population increased in certain areas and why the domestication and transition to agriculture occurred in specific places. North and Thomas (1977) stated that, due to the appearance of the first agrarian societies as a result of the demographic increase, the development of the domestication of certain species took place.

\footnotetext{
${ }^{2}$ Name given to a historical region that includes the Mediterranean Levant, Mesopotamia and Persia. It is considered as the place where the Neolithic Revolution originated, which would later spread throughout the West. Other regions that have been considered as the origin of the Neolithic in the world are: sub-Saharan Africa, southeast of present-day China, Mesoamerica, eastern North America and South America.

${ }^{3}$ Term that refers to a division of the geological time scale framed in the Quaternary. It began about two and a half million years ago and ended around 10,000 BC. During this period the last ice ages occurred, and archaeologically it coincides with the Paleolithic.
} 
Regarding the possibility that the transition to an agricultural mode of production had been the consequence of an environmental change, Gordon Childe (1928) argues that this was the cause. At the end of the Pleistocene, a climate change would have occurred that affected environmental conditions and caused an increase in temperatures that triggered the extinction of various animal and plant species that were unable to adapt to the new conditions, although it should not be overlooked, and on all with regard to the former, the incidence of human hunting activity as one of the factors that contributed to those modifications.

In relation to this, Smith (1975) raised the possibility that the extinction of some animal species had been a direct consequence of their overexploitation by Paleolithic huntergatherers. Given the scarcity of resources, they chose to change their way of life adopting agriculture as an alternative to achieve a more constant flow of food resources.

Winterhalder and Kennett share Childe's opinion, arguing that under these new environmental circumstances, hunter-gatherers were forced to change their way of life and diet, opting for the domestication of some species that, due to their characteristics, were ideal for it. At first they would have done it on a small scale until they were able to establish a properly agricultural economy (2006: 6). Olsson (2001) is also in favor of the fact that the change towards an agricultural way of life was due to environmental factors that caused genetic changes in some species, making them more prone to domestication, which facilitated the change towards an agricultural production system. According to Galor and Moav (2002), this change in the way of life increased the evolutionary potential of some individuals who were concerned with developing this new socioeconomic system, based on agriculture, in their respective human groups.

Regarding the third factor, Hayden $(1990 ; 1995)$ argues that agriculture originated in human groups that already presented a certain social inequality among their members, which, in the opinion of Lagerlöf (2002), did nothing more than rise up and provoke phenomena like slavery.

Circumscribed to the Mediterranean area, Zeder thinks that the expansion of the Neolithic Revolution in this area was due to processes of diffusion, colonization and domestication developed independently in some specific areas. This author puts forward a theory about the variation in size of domesticated animal species compared to their 
wild counterparts. In addition, he defends the theory that the extinction of some endemic animal species coincided with the arrival of human groups to various Mediterranean islands, which seems to indicate that humans played a prominent role in their disappearance $(2008: 11602)$.

Among the various proposed models that seek to elucidate the question of how the Neolithic diffusion occurred throughout the Mediterranean basin, it is worth mentioning the HBE (Human Behavioral Ecology) ${ }^{4}$. Keegan (1986) is in favor of emphasizing the importance of horticulture as a transitional stage between a hunter-gatherer economy to an agricultural one (Winterhalder and Kennett, 2006: 7). Others like Guilaine have put forward novel hypotheses such as that the Neolithic expanded in an "arithmetic" way, for which the remarkable sociocultural diversity that occurred in Europe during the early Neolithic phases must be taken into consideration. This caused moments of great development followed by stagnations that were overcome with new techniques and species that boosted the process again (2009: 267).

In general terms, it could be affirmed that the current positions differ from the previous proposals that, in a certain way, conceived Prehistory as little more than a mere succession of archaeological manifestations with its own characteristics. Currently it is perceived as a dynamic and complex stage, essential, in Hernando's opinion, to know the motivations of the different changes that occurred throughout it (1994: 140). This conception of Prehistory considers that the changes that arose at different times did not necessarily have to do with phenomena such as domestication, sedentarization and their cultural manifestations such as ceramics or the elaboration of elements in polished stone.

\section{CONSEQUENCES OF ADOPTING AGRICULTURE}

The adoption of agriculture was of enormous importance for human beings, which produced consequences, not always positive, that conditioned its later development.

\footnotetext{
${ }^{4}$ This model applies the principles of the theory of evolution and optimization to the study of human behavior and cultural diversity with the aim of examining the adaptive design of behavioral traits and human ways of life in an ecological context. It also aims to determine how ecological and social factors influence the definition of the flexibility of human behavior in its relationships with other human groups. Among other objectives, it tries to explain how variations in human behavior are the consequence of adaptive solutions to certain demands.
} 
One of the most obvious consequences occurred in its relationship with the environment, which was subjected to various modifications, some of them pernicious, to adapt it to human needs.

Hunter-gatherer groups affected their environment, but not as deeply as agricultural societies. Zeder gives Cyprus as an example, which was visited by groups of huntergatherers from the mainland during the Younger Dryas ${ }^{5}$, approximately a thousand years before the arrival by sea of the first settlers on the aforementioned island (2008: 11601). Blondel and Aronson argue that an essential characteristic of Mediterranean environments is the profound modification to which they have been subjected for thousands of years, as well as the introduction of foreign species whose presence had a negative impact on the native flora and fauna, which produced a decline of ecological diversity (Zeder, 2008:11603). In its early stages, agriculture was confined to the coastal areas of the Mediterranean, to be later introduced in other areas of Europe. These modifications on the landscape caused, at a conceptual level, that human beings began to identify with a place that they will consider their common origin (Starr, 2005: 8).

When conforming to sedentary agrarian societies, the different human groups had to make various modifications that, in some respects, were traumatic. For example, greater equality among members of hunter-gatherer groups was replaced by hierarchical social structures that led to notable inequalities. As a consequence, some individuals engaged in activities unrelated to food production, which gave rise to the social division of labour that, at times, was linked to gender, which caused important changes in their relationships. For Weisdorf (2004), the appearance of these individuals played an important role in the consolidation of the agricultural way of life and the sedentarization of human groups.

From a physiological point of view, the adoption of agriculture caused changes that, in some cases, led to a worsening of the physical condition and a greater epidemiological incidence in humans. Despite the widespread belief that the quality of life of huntergatherers was poor, thanks to the analysis of human skeletal remains from both farmers

\footnotetext{
${ }^{5}$ Brief phase of climate cooling at the end of the Pleistocene that began 12,900 years ago and ended 11,500 years ago. There is evidence that it was produced due to the impact of a comet named Clovis somewhere in North America 12,900 years ago. Another theory maintains that it was due to the eruption of the Lacher See, a volcano covered by a lake located in the present-day German region of Rhineland-Palatinate.
} 
and hunter-gatherers, it has been found that the latter were able to cover practically all their needs and enjoy even better health due to the greater variety of their diet (Armelagos et al. 1991).

The adoption of agriculture also led to a profound modification in the diet, which caused a deterioration in the oral health of farmers compared to hunter-gatherers. There was also a progressive decrease in the size of the teeth and a higher incidence of periodontal diseases (Latham, 2013). As the food consumed became easier to chew, there was a progressive gracilization of the skull whose most obvious results were a reduction in the size of the face, jaw and teeth (Larsen 1991, 2006; Sardi et al. 2004), which, as mentioned, contributed to the increase in oral diseases.

As Larsen (2006) points out, with the adoption of agriculture and a sedentary way of life, there was a demographic increase in Neolithic human populations, but, according to evidence found in some skulls, these individuals had to face a greater physical stress due to agricultural work, in addition to facing stages of malnutrition and a high incidence of diseases that, due to a greater concentration of the population, found an ideal environment for its spread (Ulijaszek 1991: 271; Armelagos et al. 1991; Papathanasiou 2005). Likewise, and due to less variety in the diet of agricultural populations, another notable effect is the reduction in stature compared to huntergatherers, in addition to less physical strength (Diamond 1987: 97).

\section{CONCLUSION}

The transition of hunter-gatherer societies to a new way of life characterized by agriculture and sedentarization had important repercussions for the future of Humanity, which culminated in the appearance of the first complex societies and the urban phenomenon.

The widespread belief that hunter-gatherer groups had a poor quality of life should be banished, according to archaeological evidence that suggests otherwise. Individuals from agrarian communities suffered the consequences of a less varied diet, in addition to being immersed in a more unequal society due to a greater hierarchy, as well as the impact of their activities on the environment, which resulted in a deterioration in their quality of life. 
The positive vision regarding the adoption of agriculture and its benefits to the human race is currently questioned by several researchers, although some perspectives, such as those presented by Diamond, may become excessively radical in their approach.

Unlike the more traditional theories, which were unable to reach a consensus, currently there is a greater rapprochement of positions, since all researchers seem to agree that the appearance and diffusion of the Neolithic was not implanted in a certain way nor in all places was adopted for the same reasons.

\section{BIBLIOGRAPHY AND INTERNET SOURCES}

- DIAMOND, J. (1987) The Worst Mistake in the History of the Human Race. Discover Magazine, Pp. 95-98.

- GUILAINE, J. (2009). La difusión de la agricultura en Europa: una difusión aritmética. Zephyrvs, n 53, pp. 267-272. http://revistas.usal.es/index.php/05147336/article/view/4987 (accessed May 2021)

- HERNANDO, A. (1994) El proceso de neolitización, perspectivas teóricas para el estudio del neolítico. Zephyrvs, n. 46, Pp. 123-142.

- LATHAM, K.J. (2013) Human Health and the Neolithic Revolution: an Overview of Impacts of the Agricultural Transition on Oral Health, Epidemiology, and the Human Body. Nebraska Anthropologist. Paper 187.http://digitalcommons.unl.edu/cgi/viewcontent.cgi? article $=1186 \&$ context $=$ n ebanthro (accessed May 2021)

- MOLIST. M. et al. (2003) El Neolític a Catalunya: entre la civilització de pastors i agricultors cavernícoles i els primers pagesos del pla. Cota Zero, n. 18; Pp. 34-53.

- STARR, H. (2005) Subsistence: Models and Metaphors for the Transition to Agriculture in Northwestern Europe. MDIA, vol.15, nº 1; pp.7-47. https://quod.lib.umich.edu/cgi/p/pod/dod-idx/subsistence-models-andmetaphorsfor-the-transition.pdf?c=mdia;idno=0522508.0015.103 (accessed May 2017) 
- WEISDORF, J.L. (2005) From foraging to farming: explaining the Neolithic Revolution. Journal of Economic Surveys, vol. 19, issue 4, pp.561-586 http://classes.uleth.ca/200701/anth1000b/foraging\%20to\%20farming.pdf (accessed May 2021)

- WINTERHALDER, B.; KENNETT, D.J. (2006) "Behavioral Ecology and the Transition from Hunting and Gathering to Agriculture". Berkeley: University of California Press, Pp. 1-21.

- ZEDER, M. (2008) "Domestication and early agriculture in the Mediterranean Basin: Origins, diffusion, and impact". Proceedings of the National Academy of Sciences of the United States of America - PNAS 105, Pp.11597-11604. 